\title{
Interjecciones en el castellano peruano
}

\author{
Interjections in peruvian castilian
}

Consuelo Meza Lagos ${ }^{1}$

\begin{abstract}
RESUMEN
En el presente trabajo, rescatamos algunas interjecciones que han sido o son usadas en el castellano local o regional del Perú y otras propias del castellano general peruano. Las recopiladas para esta exposición expresan sorpresa, asco, rechazo, desaprobación, frío, entre otros significados. Buscamos establecer su posible étimo y su localización. La obtención de estas interjecciones ha sido posible a través de la lectura de diferentes obras literarias de autores reconocidos como Alegría, López Albújar y Palma, y también de otros que no tienen la trayectoria literaria de los mencionados, pero que contribuyen a recoger la expresión de nuestro pueblo. Cabe mencionar que el corpus ha sido tomado de mi contribución personal al banco de datos de la Sociedad Peruana de Estudios Léxicos.
\end{abstract}

\section{Palabras clave}

Lexicografía, interjecciones, etimología, acepción.

\begin{abstract}
In this research, we rescued some interjections that have been or are being used at the local or regional Castilian of Peru, and other interjections typical Peruvian General Castilian. The collected words for this paper express surprise, disgust, rejection, disapproval, and cold, among other meanings. We seek to establish their possible etymon and localization. Obtaining these interjections has been possible by reading different literary works of recognized writers like Alegria, Lopez Albujar, Palma and others who do not have the literary recognition of the above, but who contribute by picking up regional idioms. It is noteworthy to point out that the corpus was taken from my personal contribution to the database of the Peruvian Society of Lexical Studies.
\end{abstract}

\section{Keywords}

Lexicography, interjection, etymology, sense (of a lexical entry).

\section{INTRODUCCIÓN}

Las interjecciones son palabras que expresan estados de ánimo como sorpresa, alegría, rechazo, entre otras significaciones. Son palabras que se especializan en la formación de enunciados exclamativos (RAE, 2010). Atendiendo a su naturaleza gramatical, las interjecciones pueden ser propias e impropias. Se llaman propias a aquellas que no provienen de otras palabras; generalmente son monosilabos. Las interjecciones impropias se crean a partir de sustantivos, adjetivos, verbos o adverbios.
Para nuestro corpus hemos considerado tanto interjecciones propias como impropias.

Conocer de dónde provienen algunas de las usadas en nuestro castellano peruano, nos dan luces para comprender una vez más, cómo la lengua se va enriqueciendo a través de los préstamos de otras que existieron en nuestro pasado (aimara y quechua, por ejemplo) y cómo el contacto del castellano con otras lenguas también ha sido y es motivo para crear nuevas acepciones o nuevas voces.

Licenciada en Educación, especialista en Lingüística Hispánica y Didáctica de la Comunicación Secundaria, con maestría en Lingüística. Es docente universitaria y de otros centros de estudio. Es autora de diversos artículos de investigación lexicográfica y realiza investigación en el campo de la lingüística. 


\section{Material y metodología}

En la investigación lexicológica, los medios de comunicación (periódicos, revistas y otros), el hombre de a pie, las producciones literarias, los anuncios publicitarios son los insumos que sirven para la recolección de datos. En nuestro caso y para nuestro propósito, las obras literarias son fuente de información de la expresión de nuestro castellano. Por ello, siendo nuestro objetivo reconocer peruanismos, hemos recurrido a obras de autores peruanos, cuyos personajes reflejan el hablar del hombre peruano. Nuestro corpus se relaciona expresamente con las interjecciones encontradas en diferentes obras y que son de uso común en el léxico del Perú.

La metodología seguida ha sido la de contrastar las definiciones de las interjecciones que pueden o no haber sido registradas por la Real Academia Española. Para ello, hemos recurrido tanto al CORDE como el CREA, así como a la $23^{\circ}$ edición del Diccionario de la Real Academia Española (DRAE). Para plantear las etimologías de nuestro corpus, hemos empleado diversos diccionarios de origen aimara, jacaru, quechua, entre otros. Estos han servido para contrastar información y para plantear posibles etimologías de las interjecciones seleccionadas.

\section{Análisis del corpus y sus posibles etimologías}

A continuación analizaremos el posible étimo del siguiente corpus: fo, carrampempe, zafa, usha, atatáu, alaláu, aj, jijuna.

\section{¡Fo!}

Como sabemos, después de la invasión de los españoles a nuestro territorio, la siguiente raza que vino a poblarnos fue la de los negros africanos, quienes llegaron en condición de esclavos desde 1527. Estos, como una forma de sobrevivir, se vieron en la necesidad de aprender el castellano $y$, tal vez sin proponérselo, nos legaron parte de su cultura y - por qué no decirlo- de su léxico. Tal es el caso de la interjección ifo!, que en el DRAE es considerada como un venezonalismo. En su primera acepción dice: "fo. interj. U. para expresar asco." Y en su segunda acepción: "coloq. Ven. U. para indicar desaprobación o rechazo". Sin embargo, Fernando Romero (1988) - aunque no todas las explicaciones que ofrece son ciento por ciento seguras, se toma en cuenta su aporte a falta de elucidaciones alternativas - registra la interjección ifo! como expresión de repugnancia o asco y además como "creación expresiva". Esta última acepción la toma de Corominas, quien documenta la expresión en 1836. Como dato, Romero nos reproduce versos de la obra "El Tamalero" de Felipe Pardo y Aliaga (1835), en la cual la interjección ifo! es usada por uno de sus personajes para expresar asco:

Está bien, se lo agradezco, ¡Fo! ¡qué oliscón! porquería. Dile a tu amo que otro día Regale un tamal más fresco.

Finalmente, Fernando Romero explica que en la lengua kikongo (hablada en la República Democrática del Congo) la voz fo se relaciona con lugares donde hay excrementos, podredumbre o cadáveres. De cualquier modo, esta interjección se confirma como expresión de asco; pero también de rechazo, como hemos podido encontrar en la obra de José "Cheche" Campos (2003, pp. 10-11):

Las noches eran infernales por la chillería de los cuyes defendiendo a sus crías, el correr de un lugar para otro de cientos de cuyes, el chillido de ratas perseguidas por los gatos, finalmente el maullido de las gatas en celo y la fuga fantasmal del gato después del engendro y desgarramiento vaginal. [...] Un día apareció el tío don Agapito Pavón y manifestó: iqué tanto gato, carajo, por qué no se los comen! ¡Ay fó!, dijo la vieja tía; sin embargo, en las profundidades de su alma de cocinera quedó prendida la mecha de la posibilidad.

En nuestro país, la expresión toma un tinte a desprecio o rechazo de la idea planteada; comer gato implica también repugnancia. Debemos añadir, además, que la expresión es en la actualidad notoriamente de uso de la gente negra que mora en Chincha. Los habitantes refieren que esta interjección ya no es muy usada en estos tiempos por gente joven, sino que se ha visto reducida solo al uso de la gente 
negra adulta, con lo cual podemos deducir que aún es conocida. Sin embargo, hay que aclarar que, según un informante que vivió en Lima en época en la cual había pocos inmigrantes, las limeñitas de estirpe decían ifo! para expresar desaprobación y rechazo, y corrobora su informe con las historietas que aparecían en el diario Última Hora, donde las jóvenes limeñas usaban esta expresión. Además, según otro informante, en la cuadra siete de Garzón, distrito de Jesús María, Lima, en la quinta "La Villanita", vivían negros que décadas atrás también hacían uso de esa interjección. En suma, es una expresión en vías de desaparición y solo queda como una marca generacional y racial. Sin embargo, se debe señalar que la Academia debería considerar la segunda acepción como uso también del Perú.

\section{¡Carrampempe!}

¡Carrampempe! Es una interjección que nos llama la atención por su proceso evolutivo. Enrique López Albújar, en su Matalaché, nos cuenta los maltratos que se infligía a los negros esclavos de la zona de Piura. En las haciendas, estos se veían forzados a la servidumbre, así como al trabajo en los cañaverales. En la obra, la sierva de María Luz, es una esclava que a la vez era su confidente. Cuando María Luz, decidida a revelarle su amor por José Manuel, el negro esclavo, le hace conocer sus afectos, la negra le responde: "-iCarrampempe! No te entiendo. Si no me abres la tutuma...

- Te lo explicaré: que él crea que quien lo haga subir sea, por ejemplo, la Rita..." (López Albújar, 1973, p. 134)

¡Carrampempe!, según el contexto, equivaldría a decir icaramba!, esto es, una expresión de sorpresa, admiración. Enrique López escribe Matalaché ambientándola en 1816, noventa años antes de su publicación. El autor muestra su deseo de ser realista y por ello trata de ajustar los personajes a sus correspondientes registros lingüísticos. La mulata hace uso justamente de una expresión usada presuntamente por gente de su raza.

Por las evidencias que hemos podido reunir de informantes de la zona, hoy nadie conoce o usa "carrampempe". La Real Academia, en su corpus histórico tampoco la consigna, pese a que la obra Matalaché se encuentra en su lista de obras consultadas. Pero ¿qué nos diría Palma en sus Tradiciones sobre este vocablo? Varios pasajes de sus narraciones contienen esta expresión y nos dan luces de su uso primigenio y sus cambios. "Pero Carrampempe, que no puede mirar la dicha ajena sin que le castañeen de rabia las mandibulas, se propuso desde el primer instante meter la cola y llevarlo a todo barrisco" ¿'No es Carrampempe el Diablo, el Maligno, el Demonio, el Tunante? ¿Ese el que mete cola para estropear las mejores intenciones?" (Palma, 1953, p. 914) Como se aprecia, en esta tradición, como en muchas otras, el vocablo es usado como sinónimo del diablo.

Fernando Romero (1987), en su diccionario de afronegrismos, presentala entrada carrampembe como interjección, y no carrampempe, y aunque cita a Palma, quien en sus Tradiciones presenta carrampempe, lo hace insistiendo en la pronunciación de la labial sonora /b/ y no de la labial sorda /p/, que en realidad sería la forma castellanizada y adoptada en el Perú. Explica que los brasileños Mata Machado Filho y Bastide encontraron la presencia de esta palabra en los negros congo-angoleños que viven en Brasil, quienes pronunciaban cariapemba, pues su origen sería nkadi ampemba que en lengua kikongo significaría "persona colérica y cruel, diablo, demonio, Satán", tal como Palma nos ilustró líneas arriba. Ahora bien, dicho sustantivo propio devino como interjección.

_Carrampempe! Pues a mí no ha
de pasarme lo que a don Enrique el
Doliente, que, no embargante ser rey
y de los tiesos, llegó un día en que no
tuvo cosa sólida que meter bajo las
narices, y empeñó el gabán para que
el cocinero pudiera condimentarle
una sopa de ajos y un trozo de jabalí
ahumado (Palma 1953, p. 673).

Según esta tradición, es Carlos III quien usa carrampempe, lo cual hace suponer, por un lado, que su uso era expandido en todas las razas y estratos sociales; por otro lado, el uso indistinto de sustantivo e interjección que, con el tiempo, tal como lo presenta Enrique López, habríase quedado instalada en el vocablo de los negros esclavos como interjección, y finalmente perderse hasta nuestros días. El proceso que 
pudo seguir es el de deformar el significante para desenmantizarlo, como en jcaracho! que alude a "carajo". Así pudo formarse jcarrampempe!

Carrampempe y fo son expresiones atribuibles a la influencia negra, legado que se perdió en el tiempo, y por tal posible origen no dejan de ser peruanas. Es una muestra de cómo las razas y costumbres, y también el idioma, son legados culturales cuando se produce el contacto.

\section{¡Zafa! y ¡Usha!}

Añádase a la lista dos interjecciones más: jzafa! y jusha! En España existe itus! y izape! para alejar al perro y al gato, respectivamente; en quechua encontramos kuq! ¡kuq, kuq! 'coc', 'coc coc' para llamar al ganado; mientras que para ahuyentar al gato existe achhuy; en el castellano andino existen jculli! y jcuchi! para arriar a los animales y izafa! y iusha! son voces empleadas para espantar a los animales; sin embargo, en el caso de estas dos últimas, cada una presenta, en su significado, una variante peculiar. Veamos el siguiente texto para determinar la significación de izafa!:

“-iZafa de aquí! —gritó María Luz, haciendo una mueca de repulsión-. QQué porquerías se ven por acá, Dios mío, qué porquerías!" (López, 1973, p. 48). María Luz, exclama "izafa!" cuando se entera de la existencia de una habitación oscura llamada "empreñadero", donde el negro José Manuel fornicaba y embarazaba a las negras y mulatas de la zona. En el ejemplo, la interjección denota una clara desaprobación de la idea, un desacuerdo con ella. Sin embargo, en este otro, percibiremos una variación en el significado: "Y yo quería separarlo a leñazo limpio: iZafa, burro, zafa!" (Gutarra, 1998, p. 49).

La expresión cobra un nuevo significado. ¡Zafa! ya no indica desaprobación, sino que se usa simplemente para espantar o poner en movimiento a los animales. Mientras que María Luz, la limeña educada en una escuela para señoritas, lleva esa expresión a la sombra del cielo piurano, un campesino de las serranías espanta a su burro con la misma palabra, de modo tal que se evidencia una doble significación.
Por otro lado, jusha! parece tener el mismo significado de izafa!; sin embargo, en la obra Amilda está en el cielo, se lee el siguiente ejemplo: "Una tarde, después del trabajo, cuando estaba llevando al bebedero al piajeno, la veo a una ñusquita, toda mechosa, pero simpatiquísima la china, arreyando chivos y oveja: iUsha cabra! ¡Ushaaá! Mi corazón casicito se para en seco. Después empezó a latir rápido." (Gutarra, 1998, p. 48). Es decir, tal como lo señala el personaje, la expresión se emplea para arrear a los animales, mas no para espantarlos. Esta sutil diferencia se aprecia mejor en otro pasaje de la misma obra: "Y en medio de la lluvia intensa vi una hilera de luciérnagas colgadas de las ropas de mi tiita Alodia. iZafa jijunas! iUshaaa!, las espanté y se fueron volando como chispazos en la noche." (Gutarra, 1998, p. 41)

Aquí izafa! es usada para espantar a los animales, y también notamos que en el texto citado se refuerza la idea y la intención utilizando iusha! De esta última, que no figura en el diccionario de Puig (1995)- lo que sí hay es jucha! interjección para azuzar o llamar al orden al perro -, podemos señalar que el sonido sibilante fricativo palatal sordo $/ \check{s} /$, representado como $<$ sh $>$, no es común en el español moderno, sino en variedades de quechua central y norteño, lo cual nos hace suponer que no es de origen peninsular sino posiblemente quechua. En el quechua ancashino (Parker y Chávez, 1976), el préstamo "oveja" toma la forma de uusha, mientras que en el quechua de Cajamarca (Quezada, 1976) es wisha; en el de Pacaraos, uysha; y en el jacaru de Cachuy, uwishi (Belleza, 1995).

Por lo visto, es posible que haya una relación entre la interjección y el nombre que la oveja recibe en lenguas vernáculas. En jacaru, la voz que se usa para arrear ganado menor (ovejas y cabras), y para aves de corral es jisha (Belleza, 1995). Podemos postular que pudo haberse dado esta evolución: uusha > wisha > jisha, ya que la diptongación "wisha" a partir de un lexema como "uusha" no es rara ${ }^{2}$; y, por otro lado, existe una correlación de palabras que empiezan con $/ \mathrm{w} /$ y variantes que empiezan con fricativa

2 Por ejemplo, en la mayoría de variantes regionales del quechua peruano, "cara" es uya, pero en el quechua ecuatoriano y en el peruano de Pacaraos ocurre wiya. 
velar - En aimara tenemos wiphilla 'tripa' y wiskhu 'ojota' con sus respectivas variantes jiphilla y jiskhu. Aunque en su origen jusha! se haya aplicado al arreo de las ovejas, su uso se extendió al arreo de cabras y otros animales (cf. jacaru jisha). De las dos interjecciones, izafa! es de uso más extendido en nuestro país, mientras que jusha! se restringe a las zonas andinas de nuestro territorio por la actividad económica desarrollada por sus pobladores.

\section{¡Alaláu!}

Siguiendo con el posible étimo quechua de algunas de las interjecciones debido al contacto del quechua o aimara con el castellano, se advierte la presencia de interjecciones como jalaláu! 'iqué frío!', jatatauya! 'iqué asco!', 'iqué feo!'. Coexiste entre nosotros jalaláu! para denotar "sentir frío", no solo en la sierra, sino también en la costa. En el DRAE, en su última edición (23 edición publicada en octubre de 2014), la palabra se registra así: "alaláu. Interj. Bol. alalay", y en alalay "Interj. Bol. U. para denotar sensación de frío". Sin embargo, ya Juan de Arona en su Diccionario de peruanismos (1888) determinó a la interjección como un arequipeñismo: "Alaláu: Arequipa. Exclamación de frío". Más adelante, Álvarez Vita (1990), siete años antes que el Vocabulario de Peruanismos de Ugarte Chamorro (quien también registra alalau), la presenta como un peruanismo: alalay "Bol. y Perú (Zona Andina) Alalau"; esta remisión nos lleva a ver el significado de alalau: "Perú (Zona Andina) Exclamación usada para indicar que hace un frío muy intenso." Esta interjección que denota 'sentir frío' es muy antigua en el Perú (es precolombina), y no debía registrarse en el DRAE solo como parte del uso boliviano (inconsecuencia de los peruanos lexicógrafos). Además, si revisamos el diccionario quechua de Gonçález Holguín encontraremos "Alau, alalau. Quejido del que tiene frío.". En suma, es palabra del léxico compartido del quechua y del aimara que en la costa es usada por inmigrantes andinos, expresión de la que no hacemos ningún esfuerzo por entenderla porque nos resulta muy familiar.

\section{¡Atatáu! y ¡Aj!}

¿Y qué sucede con las expresiones atatáu (o su variante atatauya) y aj? Se usan para denotar repulsión o asco, algo muy distinto de lo que el DRAE menciona en el caso de aj. Aquí un ejemplo de atatauya:

-iHermano! iPerdóneme! Le pido perdón delante de mis compañeros... -dijo.

Algo, algo más iba a decir y hacer. Se inclinó, empezó a inclinarse. El Hermano había levantado las manos. —iNo! —gritó Lleras—. iNo! iEs negro, Padrecito! iEs negro! jAtatauya! ${ }^{1}$

De un salto bajó al patio empedrado, lo cruzó a gran velocidad, entró a la sombra de la bóveda [...] (Arguedas, 1970, p. 152)

Al pie de página de la obra se puede leer:

"2 Interjección de asco". El mismo autor registra esta palabra ahora en su variante atatao en su obra Yawar fiesta:

Desde Sillanayok' se ve la capilla de Chaupi, junto a una piedra grande, se ve brillante y larga, con su torre blanca y chata.

-iAtatao! ${ }^{3}$-dicen los comuneros de los otros barrios - Parece iglesia de misti. (Arguedas, 1978, p. 8).

Al pie de la página aparece una nota aclaratoria para el lector: "Interjección de asco".

En el DRAE, la primera acepción de atatay se asigna a Bolivia como expresión de dolor (aquí se atienen al significado aimara de la raíz); la segunda va para Ecuador, como expresión de asco (significado que la raíz tiene en quechua). Por otro lado, Álvarez Vita, coincidiendo con la edición vigente del DRAE -la vigésima tercera-, la registra en su variante jatatay! como voz quechua usada en Bolivia, Ecuador y Perú, y hace la remisión a atatau: "Exclamación de dolor, asco o repulsión." . Le agrega el significado de "sentir dolor". Hay que aclarar que atataw o atatay existen en quechua y en aimara, pero existe una diferencia: en la primera lengua expresa asco o desagrado; en la segunda, dolor. A continuación un ejemplo de Arguedas:

-iTurucha, carago! -diciendo, se retaceó el chaleco y la camisa; mostró el costillar corneado. 
- Atatau yawarcha! —gritó.

Como de una pila hizo brincar su sangre al suelo. (Arguedas, 1978, $p$. 27)

El personaje Honrao Rojas, quien había sido embestido por el toro, muestra su cuerpo ensangrentado y luego grita jatatau! en señal no de asco, sino de dolor (significación que esta raíz posee en aimara, como se señala líneas arriba). Esta última acepción, sin embargo, es rarísima en la costa (más que nada la emplean los migrantes que vienen de la sierra); se la conoce más bien en las zonas andinas donde se habla el quechua. Es muy común escucharla en el Perú en su primera acepción (de asco o repulsión) hasta en personas que se dicen de origen limeño, al igual que en el caso de los pobladores de la selva. En otras palabras, esta interjección de origen quechua ha pasado a ser parte del uso lingüístico de muchos peruanos.

Seguramente salta una objeción: si la obra de Arguedas se escenifica en una zona de habla quechua, específicamente Puquio, en Ayacucho, ¿por qué se afirma que atatau, en su acepción de "dolor" sea de origen aimara y no quechua? Al respecto, se debe tener en cuenta que los estudios toponímicos (Cerrón-Palomino, 2000) señalan que en toda esta área, antes predominaba la lengua de los collas. Como consecuencia de ello, es muy probable que haya quedado un sustrato aimara.

Mucho más generalizado es el uso de jaj!, para expresar asco o repulsión. En Lima, la interjección ha cobrado vigorosa vigencia. Personas de todos los niveles sociales la emplean en cualquier momento. La obra La casa verde lo registra así:

A solas era todavía peor, aj, se te caen los dientes, aj, tienes la cara picada, aj, tu cuerpo ya no es el de antes, aj, se te chorrea, pronto vas a estar como las viejas huambisas, aj, y todo lo que se le ocurría. (Vargas Llosa, 2001, pp. 134135)

Este vocablo podría ser un préstamo aimara, tal como podemos verificar en un diccionario de Ayala Loayza (1988), en el que encontramos aj' (la grafía <j'> representa una consonante fricativa postvelar sorda, $<\mathrm{x}>$ en la ortografía usual del aimara, que suena como una jota pero más áspera) como palabra que expresa asco. Sin embargo, al revisar el diccionario de de Lucca (1987) para certificar su presencia en el aimara altiplánico no encontramos ni "aj" ni "ax", con lo que podemos suponer que más bien podríamos estar ante un préstamo del castellano al aimara.

Otra hipótesis sería la de un caso de coincidencia entre estas dos lenguas. Reparemos cómo se produce el canto del gallo: "cocoroco" o "quiquiriquî" en castellano, "Kikeriki" en alemán, "cocoricó" en francés. La muy parecida realización de esta palabra no puede llevarnos a afirmar que en este caso las tres lenguas han hecho uso del préstamo lingüístico, sino que cabe más bien suponer una simple coincidencia.

Para concluir, debemos anotar que la interjección iaj! no es usada recientemente; sabemos que desde hace muchos años está vigente en nuestro medio. El DRAE registra lo siguiente: "aj. (De ax). m. achaque (enfermedad habitual). U. m. en pl.", que no refleja el uso peruano. Sabemos que jaj!, como interjección, fue propuesta por la Comisión Lexicográfica de la Academia Peruana de la Lengua, pero no fue admitida por la Academia de Madrid (Baldoceda, 2002). Siendo una voz ampliamente usada en todo el Perú, debería estar en el DRAE.

\section{¡Jijuna!}

¡Jijuna! (de "hijo de una..."), interjección muy extendida en nuestro país, es recogida por Álvarez Vita (1990) como "hijo de una"; y Miguel Ángel Ugarte Chamorro (1997) la definiría más específicamente como "hijo de puta". Con esta acepción la encontramos en textos más explícitos, como: "Jijuna gramputas, ya verán, les va a suceder lo mismo que a la señorita Tula, rezongaba María de la Buena Dicha de la piedad y los Santos Oleos, sentada frente al televisor (...)" (Campos, p. 7).

La palabra también se encuentra registrada en la obra Los perros hambrientos:

Uno de los gendarmes bajó del caballo y le dio una bofetada, tirándola al suelo, donde la Martina se quedó hecha un ovillo, 
gimiendo y lamentándose. Amarró seguidamente al Mateo por las muñecas, los brazos a la espalda. La soga era de cerda y el Mateo pujaba sintiendo la carne corroída. El de galones acercó su caballo y le dio dos foetazos en la cara.

- Así, mi cabo — rió el otro mientras montaba-, pa que aprienda a cumplir con su deber este cholo animal...

Y luego ambos:

-Anda...

-Camina, so jijuna... (Alegría, 1997, p. 41).

Sin embargo, los valores semántico y gramatical de esta palabra han variado considerablemente $y$ de manera concatenada: a) de palabra ofensiva a palabra no ofensiva; b) de interjección a sustantivo, término de preposición, como es el caso del nombre de una discoteca limeña en Barranco "Don Jijuna", donde se aprecia la banalización de su carga ofensiva o vulgar; c) de la anterior estructura como base, pasa a adquirir una capacidad de calificación ponderativa propia de un adjetivo o frase adjetival. Así, nos encontramos con que en algún restaurante de la capital peruana ofrecen el plato a la carta "cordero a la jijuna". En el siguiente texto se lee:

La abuela chola enseñó los secretos del cordero a la jijuna, del cuy chactado, de las condimentaciones para el picante de cuy, enseñó a preparar el cuy platero que se preparaba en las minas de mercurio de su tierra, Huancavelica; a escondidas aprendieron a tomar los calientitos preparados con alcohol rebajado o con ron de quemar que le llamaban el verdecito, en fin... (Campos, 2003, p. 9).

¿Es correcto afirmar que es comida reciente? Dada la difusión de una onda culinaria y gastronómica llena de nuevos nombres, se podría pensar que así es. Sin embargo, informantes de la zona de Chincha, de más de ochenta años de edad, responden que es parte de la cocina de antaño que se ha ido perdiendo con el tiempo. El cordero "a la jijuna" es plato típico preparado en San Luis de Cañete, pero actualmente solo para la fiesta patronal del 22 de agosto (por el santo patrón San Luis Gonzaga). Consiste en un macerado de un día para otro con ingredientes principales como el comino (muy usado en la cocina del lugar), pimienta, ají colorado, huacatay, chicha de jora y vino seco. Este preparado se unta sobre el carnero o cordero y luego se lo lleva a asar al palo. Lo llaman "cordero a la jijuna" para denotar que estaría no solo delicioso, sino muy delicioso. Por último, se puede afirmar que en tanto valor ponderativo, su significación es algo parecida a "esto está maldito", para expresar que algo está muy bien.

Las interjecciones presentadas y sustentadas como de uso generalizado en nuestro país, como es el caso de izafa!, ialaláu!, iaj!, iatatau! y ijijuna! deberían ser tomadas en cuenta en el DRAE. En el caso de ifo!, se tendría que incluir en el mencionado lexicón la marca Perú, para que no se vea esta palabra como patrimonio exclusivo de Venezuela. icarrampempe! y iusha! son voces que se han circunscrito a un área local (ahora extinta), la primera; y como regionalismo que aún está vigente en el habla de sus usuarios, la segunda.

\section{CONCLUSIONES}

1. "Carrampempe" denota admiración, sorpresa, y equivale a "caramba" (expresión de extrañeza o enfado), según se deduce por el contexto. Es una palabra desenmantizada, pues venida como préstamo de los negros esclavos, aludía al Diablo, al Maligno y a toda la gama de acepciones a este referente. Pese a las indagaciones realizadas, no se ha podido encontrar fuentes corroborantes de su vigencia en estos tiempos.

2. "Fo" denota asco o repulsión, según hemos podido constatar en textos escritos. El origen sería de una lengua africana, tal como hemos indicado.

3. Respecto de "alaláu" (expresión de frío) y "atatáu" o "atatauya" (expresión de asco o desagrado), señalamos que es de étimo quechua y aimara la primera; mientras la segunda ("atatáu" o 
"atatauya") es también compartida por ambas lenguas, pero con significado diferente (expresa dolor en aimara y asco en quechua).

4. "Usha" tiene un posible étimo quechua por la presencia del fono Śšș y por una posible derivación fonética y semántica de voces como uusha, wisha o uysha.

5. Respecto de "aj" (interjección que manifiesta asco o desagrado), cuya inclusión en el DRAE es urgente, podría postularse que es un préstamo del español al aimara.

6. "Zafa" y "jijuna" son interjecciones de uso muy frecuente en el habla general del Perú. Ambas han sufrido procesos de cambio. En la primera palabra, se observa una nueva acepción en la zona costera, a diferencia de la serrana; se ha producido una ampliación semántica. En la segunda, ha perdido su carga ofensiva para contener una carga más bien expresiva atenuada. 


\section{REFERENCIAS}

Adelaar, Willem F. H. (1979) Léxico del quechua de Pacaraos. Lima: Centro de Investigación de Lingüística Aplicada de la Universidad Nacional Mayor de San Marcos. Lima.

Alegría, C. (1997) Los perros hambrientos. Lima: Colección Autores Peruanos.

Álvarez, J. (1990) Diccionario de peruanismos. Lima: Librería Studium.

Arguedas, J. M. (1970) Los ríos profundos. Lima: Editorial Universitaria S.A.

Arguedas, J. M. (1978) Yawar fiesta. Buenos Aires: Editorial Lozada.

Ayala, J. (1988) Diccionario español-aymara aymara-español. Lima: Editorial Juan Mejía Baca.

Baldoceda, A. (2002) Resultados de la propuesta lexicográfica peruana en el diccionario de la Real Academia. Boletín No 36. Lima: Academia Peruana de la Lengua. Pp. 85-162.

Belleza, N. (1995) Vocabulario jaqaru-castellano castellano jacaru / aimara tupino. Cusco: Centro de Estudios Regionales Andinos Bartolomé de las Casas.

Calvo, J. (2014) Diccionario etimológico. Lima: Universidad Ricardo Palma.

Campos, J. (Cheche). (2003) Las negras noches del dolor. Lima: Ediciones INAPE. 10-11.

Cerrón-Palomino, R. (2000) Lingüistica aimara. Cusco: Centro de Estudios Regionales Andinos Bartolomé de las Casas

De Lucca, M. (1987) Diccionario práctico Aymara-Castellano/Castellano -Aymara. La Paz: Los amigos del libro.

Gutarra, R. (1998) La Amilda está en el cielo. Trujillo: Camión Editores

López Albújar, E. (1973) Matalaché. Lima: Ediciones Peisa.

Parker, Gary J. y Chávez, A. (1976) Diccionario quechua Ancash-Huailas. Lima: Ministerio de Educación e Instituto de Estudios Peruanos.

Palma, R. (1953) Tradiciones peruanas. Madrid: Ediciones Aguilar, S. A.

Paz Soldán y Unanue, P. (Juan de Arona) (1938 Ś1883Ș) Diccionario de peruanismos. París, Francia: Desclée De Brouwer.

Perroud, P. y Chouvenc, J. M. (1970) Diccionario castellano kechwa castellano. Lima: Padres Redentoristas.

Puig T., E. (1995) Breve diccionario folclórico piurano. Piura: Universidad de Piura.

Quesada, F. (1976) Diccionario quechua Cajamarca-Cañaris. Lima: Ministerio de Educación e Instituto de Estudios Peruanos. 
Real Academia Española. (2014) Diccionario de la lengua española. Madrid: Espasa Calpe S. A., 23.a edición.

Real Academia Española. (2010) Nueva gramática de la lengua española Madrid: Espasa Calpe S. A.

Romero, F. (1987) Quimba, Fa, Malambo, Neque. Afronegrismos en el Perú. Lima: Ediciones Instituto de Estudios Peruanos.

Santillana, S. A. (2000) Diccionario enciclopédico. (15 tomos). Lima: Santillana S. A. y El Comercio.

Tauro del Pino, A. (2000) Enciclopedia ilustrada del Perú (17 tomos). Lima: Peisa y Editora El Comercio, 3.a edición.

Ugarte Chamorro, M. (1996) Vocabulario de peruanismos. Lima: Universidad Nacional Mayor de San Marcos.

Vargas Llosa, M. (2001) La casa verde. Lima: Peisa.

Fecha de recepción: 01-06-17

Fecha de aceptación: 07-07-17 